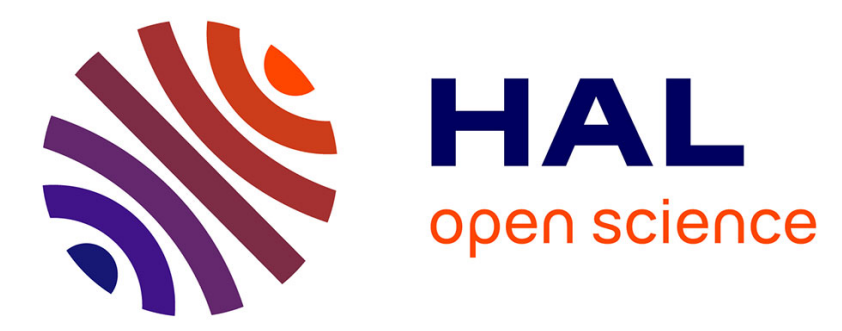

\title{
Les présidents américains et le sport : pouvoirs de l'exercice et exercice du pouvoir, de Theodore Roosevelt à Barack Obama
}

Peter Marquis

\section{- To cite this version:}

Peter Marquis. Les présidents américains et le sport : pouvoirs de l'exercice et exercice du pouvoir, de Theodore Roosevelt à Barack Obama. Histoire@Politique: revue du Centre d'histoire de Sciences Po, 2014, Cultures sportives et cultures politiques. Le cas des chefs d'Etat et de gouvernement dans le monde au XXe siècle, 23 (2), pp.10. 10.3917/hp.023.0010 . hal-02061245

HAL Id: hal-02061245

https://hal-normandie-univ.archives-ouvertes.fr/hal-02061245

Submitted on 7 Mar 2019

HAL is a multi-disciplinary open access archive for the deposit and dissemination of scientific research documents, whether they are published or not. The documents may come from teaching and research institutions in France or abroad, or from public or private research centers.
L'archive ouverte pluridisciplinaire HAL, est destinée au dépôt et à la diffusion de documents scientifiques de niveau recherche, publiés ou non, émanant des établissements d'enseignement et de recherche français ou étrangers, des laboratoires publics ou privés. 
Peter Marquis, « Les présidents américains et le sport : pouvoirs de l'exercice et exercice du pouvoir, de Theodore Roosevelt à Barack Obama », Histoire@Politique. Politique, culture, société, n²3, mai-août 2014 [en ligne, www.histoire-politique.fr]

\title{
Les présidents américains et le sport : pouvoirs de l'exercice et exercice du pouvoir, de Theodore Roosevelt à Barack Obama
}

\author{
Peter Marquis
}

«Voici mon plan de jeu pour l'économie » annonçait Nixon en 19691, utilisant une expression venue du football américain ; « Il s'est fait tamponné » remarqua George Bush en 1991, lorsque Colin Powell revint du Moyen-Orient sans avoir convaincu l'Iraq de se retirer du Koweït ; " [Si Romney avait été président], les employés de l'industrie automobile auraient chauffé le banc pour toujours » déclara le candidat Obama lors de la campagne de $2012^{2}$. La rhétorique des hommes politiques américains regorge d'expressions empruntées au jargon sportif. Elles jouent trois fonctions a minima : métaphoriser des stratégies (on pense au «pressing toutterrain » de G.H.W. Bush face à l'Iran ${ }^{3}$ ) ; optimiser, dans une perspective de relations publiques, l'image du président comme «Monsieur tout-le-monde qui apprécie le sport » (regular sports-loving guy) ; et (ré)affirmer la masculinité de la fonction présidentielle ${ }^{4}$.

Ce recours à l'activité physique compétitive trouve un écho particulier aux États-Unis, pays où le sport est, peut-être davantage qu'ailleurs, une lingua franca qui innerve toute la population et alimente plusieurs pans de l'économie (médias, droits télévisuels, produits dérivés). L'analyse diachronique le prouve: de Theodore Roosevelt (président de 1901 à 1909) 5 à Barack Obama (2008-), une grande majorité des occupants de la Maison Blanche cultivèrent des relations étroites avec le sport ou le monde du sport affichant en public leur pratique, défendant ses bienfaits pour la vitalité de la nation, ou l'utilisant à des fins de communication politique. À force des'associer régulièrement au monde du sport, ils devinrent aux yeux du public des « présidents sportifs ».

\footnotetext{
1 Mes remerciements vont à Patrick Clastres et aux relecteurs anonymes pour leurs suggestions d'amélioration et d'approfondissement. Cet article s'accompagne d'un mini site web consultable à cette adresse : http:// lespresidentsamericainsetlesport.wordpress.com/.

2 « Nixon Game Plan Appears Winner », The Victoria Advocate, 6 avril 1970 ; « He was stiff armed », G.H.W. Bush, citédans Warren Goldstein, «Sports in the 20th Century », Mary KupiecCayton, ElliottJ. Gorn, et Peter W. Williams (dir.), Encyclopedia of American Social History, New York, Scribner, 1993; Obama, citédans Kathleen Hennessey et Christi Parsons, « Obama Employs Sports Metaphors in Ohio », Los Angeles Times, 3 septembre 2012.

3 Cité dans Pierre Grosser, Les temps de la guerre froide : réflexions sur l'histoire de la guerre froide et sur les causes de sa fin, Bruxelles, Editions Complexe, 1995, p. 421.

4 A J. Moore et D. Dewberry, «The Masculine Image of Presidents As Sporting Figures: A Public Relations Perspective », SAGE Open, 23 août 2012, vol. 2, n 3. DOI 10.1177/2158244012457078 [lien consulté le 8 février 2014].

5 Cette étude commence avec Theodore Roosevelt car il fut le premier président du XXe siècle, il grandit dans les années 1870, époque où les sports se professionnalisèrent et se transformèrent en spectacle, et car sa pratique du sport (jujitsu, chasse, etc.) fait de lui l'inventeur de la figure du « président sportif ».
} 
Peter Marquis, « Les présidents américains et le sport : pouvoirs de l'exercice et exercice du pouvoir, de Theodore Roosevelt à Barack Obama », Histoire@Politique. Politique, culture, société, n²3, mai-août 2014 [en ligne, www.histoire-politique.fr]

Mais que cache cette formule? S’agit-il d'un président qui pratique le sport ? Dans ce cas, est-il un sportif occasionnel ou de haut niveau? Sa pratique date-t-elle de l'enfance, du lycée, de son arrivée à la Maison Blanche? L'expression signifie-t-elle davantage que ce président est amateur de sport ? Dans ce cas, se rend-il au stade ou préfère-t-il le confort de son salon ? Suit-il une équipe fétiche ou se détache-t-il de tout esprit partisan? De plus, entend-on par «être sportif », être en bonne santé, voire faire l'éloge du sport, sans forcément y participer ? Enfin, de quels sports parlet-on ? Le tennis, l'alpinisme, le golf ou le football américain ne sont-ils pas, dans leur nature et dans leurs connotations, impossibles à comparer 6 ?

La difficulté qu'il y a à définir le « président sportif » invite à lui préférer le concept de «culture sportive». Mais de nouveau, une série de questions se pose : s'agit-il d'un savoir ou d'une façon d'être au monde? La « culture sportive » engloberait des savoirs et des pratiques, des usages sociaux et des discours, qui ont la particularité de tous se nicher au coeur de l'individualité, participant ainsi au rapport que l'individu entretient avec le monde.

Un de problèmes majeurs est que dans l'état actuel des connaissances, et malgré des progrès conséquents en anthropologie, en biologie, ou en sociologie, on ne sait toujours pas exactement ce que le sport fait aux individus et ce que les individus font avec le sport ${ }^{7}$. Pour le sujet qui nous concerne, quel rôle joue le sport dans la vie d'un président? Aussi bien sur le plan de son parcours biographique que de ses affinités, de ses sensibilités, de sa façon de réagir dans l'adversité, en temps de crise, mais aussi de sa façon de négocier sa place dans un collectif, de gérer la question récurrente de la victoire et de la défaite? C'est toute sa personne qui semble irriguée par sa culture sportive.

C'est bien à la dimension personnelle de la présidence que cet article espère contribuer en s'intégrant dans un renouveau des presidential studies. Constituée par des historiens du politique et des politologues tels que J ulian Zelizer, cette nouvelle histoire présidentielle réexamine l'exercice du pouvoir dans son intimité, sa complexité, sa globalité, sa dimension horizontale et son temps long, au-delà des cycles électoraux et de l'insatiabilité des médias modernes ${ }^{8}$. Parallèlement, se sont développées depuis quelques années des études sur le rôle des émotions en politique, ainsi que sur le corps, dans le cadre d'une étude de la performance en politique ${ }^{\text {. }}$

\footnotetext{
${ }^{6}$ Dans la panoplie des sports, le golf occupe une place particulière. Si en France, il pâtit encore d'une réputation de sport élitiste, aux États-Unis il est connoté à la fois plutôt péjorativement en tant que loisir des classes dominantes oisives, mais aussi en tant qu'activité de l'honnête homme qui se retire du monde pour décompresser et profiter de ses amitiés masculines et professionnelles. C'est le sport incontournable de tous les présidents, depuis le début du $\mathrm{XX}^{\mathrm{e}}$ siècle. Un cliché est que « sur le parcours de golf, on voit la vraie personne », cité in « Rice'sDiplomaticSkillsExtend to Golf Course », New York Times, 7 février 2013. J e remercie Pierre Grosser de m’avoir signalé cet article.

7 Pour quelques pistes, Sébastien Darbon, «Les pratiques sportives au filtre de l'anthropologie », La Revue pour l'histoire du CNRS, $\mathrm{n}^{\circ} 26,2010$, DOI : 10.4000/histoire-cnrs.9268 [lien consulté le 8 février 2014].

8 Pour une présentation de ce renouveau historiographique, Julian Zelizer, «Beyond the PresidentialSynthesis », in A Companion to Post-1945 America, Jean-Christophe Agnew et Roy Rosenzweig, dir. (J ohn Wiley\& Sons, 2008), p. 345-370.

9 Voir Philippe Braud, L'émotion en politique, Paris, Presses de Sciences Po, 1996 ; Christophe Traïni (dir.), Émotions... Mobilisations !, Paris, Presses de Sciences Po, 2009 ; George E Marcus, « The Place of Emotion in International Relations Scholarship », E-International Relations, http://www.eir.info/ 2013/ 10/ 02/ the-place-of-emotion-in-international-relations-scholarship/ [lien consulté le 3 juin 2014]. Ces travaux étudient le politique du point de vue de l'« économie émotionnelle » des citoyens, et
} 
Peter Marquis, « Les présidents américains et le sport : pouvoirs de l'exercice et exercice du pouvoir, de Theodore Roosevelt à Barack Obama », Histoire@Politique. Politique, culture, société, n²3, mai-août 2014 [en ligne, www.histoire-politique.fr]

Étudier la culture sportive d'un président entre dans ce nouveau chantier historiographique, car elle se situe à l'interface entre le public et l'intime, et influence (du moins j'en fais l’hypothèse) le processus de décision (policy-making), donc toute une partie de la fabrique de la politique présidentielle

Le projet de cet article est donc de questionner le rôle joué par le sport dans la formation des présidents américains et dans leur pratique du pouvoir sur tout le $\mathrm{XX}^{\mathrm{e}}$ siècle et la première décennie du XXIe siècle, dans l'espoir de contribuer à une histoire politique renouvelée par sa préoccupation pour les à-côtés, l'en-dedans et l'en-deçà du pouvoir politique traditionnel. Mon argument est que sur la période concernée l'exercice du pouvoir politique fut inséparable du pouvoir donné à l'exercice sportif. L'historiographie étant très lacunaire, les sources utilisées proviennent de biographies, d'articles de presse, et de rétrospectives pour le grand public ${ }^{10}$. L'essai est construit selon trois grandes étapes : les pratiques sportives de chaque président et leur utilisation médiatique, un examen de l'essence sportive du président des États-Unis, et enfin des pistes sur les liens entre sport, intimité de la présidence et exercice du pouvoir.

\section{Le sport, élément consubstantiel à la figure présidentielle}

L'opinion communément admise, largement entretenue par la presse ${ }^{11}$, veut que les rapports entre sport et présidence soient naturels, du simple fait que les présidents américains furent dans leur grande majorité des sportifs et/ ou des amateurs de sport. Ce qui suit est un récit volontairement non critique des pratiques sportives des présidents tel que l'on peut le reconstituer à partir des biographies, mémoires ou témoignages existants. Suit une présentation de leur usage du sport à des fins communicationnelles.

\section{Les présidents et leur pratique sportive}

Barack Obama est un basketteur régulier et compétitif, inconditionnel de l'émission Sport Center sur ESPN. Son prédécesseur, G. W. Bush, fut joueur de baseball au lycée et surtout, avant de se lancer en politique, il fut copropriétaire des Dallas Cowboys, équipe de ligue majeure de base-ball. Bill Clinton était admiré pour son swing par les

non des élus. Sur la performance en politique, David Schlossman, Actors and Activists: Performance, Politics, and Exchange Among Social Worlds, London, Routledge, 2002, p. 7.

${ }_{10}$ Contre toute attente, aucun ouvrage universitaire n'offre une synthèse sur le sujet ; il n'y a même aucune entrée «sport» dans Michael Genovese (dir.), Encyclopedia of the American Presidency, Infobase Publishing, 2009. Les deux sources principales sont donc l'ouvrage grand public de J ohn Sayle Watterson, The Games Presidents Play: Sports and the Presidency, Baltimore: Johns Hopkins University Press, 2006 ; et les pages web très complètes du « Miller Center » de l'Université de Virginie http:// millercenter.org/president [lien consultéle 3 juin 2014].

${ }^{11}$ Sélection d'articles illustrant cette thèse : " How the U.S. President Became the Nation's Star Athlete », History, http:// www.history.com/news/how-the-u-s-president-became-the-nations-star-athlete [lien consulté le 7 février 2014] ; "Rich History of U.S. Presidents and Sports », Pipe Dream, http:// www.bupipedream.com/archive/ 5718/rich-history-of-us-presidents-and-sports/ [lien consulté le 27juin 2012] ; "The List: American Presidents with Sports Links », FanNation.com, http:// www.fannation.com/si blogs/for the record/posts/50661-the-list-american-presidents-withsports-links [lien consulté le 7 février 2014]. 
Peter Marquis, « Les présidents américains et le sport : pouvoirs de l'exercice et exercice du pouvoir, de Theodore Roosevelt à Barack Obama », Histoire@Politique. Politique, culture, société, n²3, mai-août 2014 [en ligne, www.histoire-politique.fr]

journalistes de Sports Illustrated ${ }^{12}$. Et que dire de son prédécesseur, G. H. W. Bush, qui fit les grandes heures de l'université Yale en occupant le poste de première base dans l'équipe de baseball vers 1950 ?

\section{[Pour voir les photos, cliquer sur les liens suivants : $\underline{\text { Obama }}$; Bush Jr ; $\underline{B u s h ~ S r}$ ]}

Dans cette geste des présidents sportifs, Ronald Reagan est l'athlète complet: au lycée et au college d'Eureka (Illinois), il jouait au football, au basket, et pratiquait la natation (on dit qu'il sauva soixante-dix-sept vies en tant que maître-nageur sauveteur). Puis, il fit carrière comme commentateur sportif à la radio, capable d'inventer des séquences de jeu quand bien même les télégrammes venus des stades ne lui parvenaient plus. Ce talent d'improvisation lui valut une carrière d'acteur à Hollywood où il incarna souvent des héros sportifs, comme un joueur de football dans KnuteRockne (1940), son plus grand succès.

\section{[Pour voir les photos, cliquer sur les liens suivants : Reagan]}

Même le discret J immy Carter a sa place dans ce grand récit des présidents sportifs : joueur de basket au lycée, puis de football à l'académie navale d'Annapolis, il courait souvent et pratiquait le softball en famille ou entre amis durant ses années à la Maison Blanche.

Gerald Ford mériterait à lui seul un chapitre entier dans cette histoire tant son passé de sportif était hors du commun à son arrivée à la Maison Blanche. En 1933 et 1934, il mena les Wolverines, équipe de football de l'université de Michigan, à deux titres de champions universitaires. Son diplôme en poche, plusieurs équipes professionnelles voulurent l'engager, mais Ford déclina, préférant entrer à Yale où on lui proposait une place bien payée d'entraîneur; il pensait de cette manière intégrer plus facilement la faculté de Droit, conformément à son projet de devenir avocat. Régulièrement adoubé par la presse «président américain le plus sportif de l'histoire », Ford demeura dans ses années à la Maison Blanche un sportif accompli, pratiquant le golf, le tennis, la natation, l'équitation, ou le ski ${ }^{13}$.

\section{[Pour voir les photos, cliquer sur le lien suivant : Ford]}

Richard Nixon lui aussi occupe une place de choix dans ce panthéon, mais à l'inverse de Ford, son rêve de devenir champion de football ne fut jamais réalisé. À Whittier College, en Californie, le jeune Nixon était un frêle linebacker (capitaine de la défense) qui ne quittait le banc des remplaçants que lors des matches où son équipe était sûre de gagner. Il développa ensuite une culture sportive encyclopédique qui lui valut les éloges des connaisseurs, notamment lorsqu'il fut capable, en 1972, de fournir non pas une mais quatre listes à un journaliste qui lui demandait quelle était son équipe de baseball idéale ${ }^{14}$. De l'avis général, ces listes témoignaient d'une érudition

\footnotetext{
12 Rick Reilly, « Perfect Pard. President Clinton Teamed with the Author for a Friendly Round of Golf at Congressional », 12 juin 1995, http://sportsillustrated.cnn.com/vault/article/magazine/MAG1006697/index.htm [lien consulté le 7 février 2014].

13 «The Top 10 Most Athletic Presidents in U.S. History », Dallas Observer, http:// blogs.dallasobserver.com/sportatorium/2008/11/the top 10 most athletic presi.php, [lien consulté le 27juin 2012] ; «Top 10: Obama's Place Āmong Āthletic Presidents », MaxPreps, http:// www.maxpreps.com/news/ wjUx4 rk0kaBNg7MiXKCHw/top-10--obamas-place-amongathletic-presidents.htm [lien consulté le 7 février 2014].

14 Nicolas Sarantakes, «Richard Nixon, Sportswriter: The President, His Historical All-Star Baseball Team, and the Election of 1972 », J ournal of Sport History, vol. 24, no 2 (1997), p. 194.
} 
Peter Marquis, « Les présidents américains et le sport : pouvoirs de l'exercice et exercice du pouvoir, de Theodore Roosevelt à Barack Obama », Histoire@Politique. Politique, culture, société, n²3, mai-août 2014 [en ligne, www.histoire-politique.fr]

et d'une acuité hors du commun, compliments qui flattèrent celui qui aurait aimé être journaliste sportif ${ }^{15}$. Durant ses deux mandats, il s'évertua à se montrer proche de «la majorité silencieuse», notamment en pratiquant un des sports favoris des américains, le bowling.

\section{[Pour voir les photos, cliquer sur le lien suivant : $\underline{\text { Nixon] }] ~}$}

Autre avatar célébré du « président sportif », le jeune et souriant J ohn Kennedy, que l'on voit sur d'innombrables photographies, ici en capitaine à la barre du voilier familial (il avait d'ailleurs obtenu un prix de navigation à Harvard), là en golfeur, promenant son impeccable élégance vestimentaire sur les greens, là en père de famille ordinaire jouant au touch football, sport traditionnel dans le clan Kennedy ${ }^{16}$.

\section{[Pour voir les photos, cliquer sur le lien suivant : Kennedy]}

Dwight Eisenhower, est aussi dépeint comme un grand « président sportif ». Dans sa jeunesse «le football et le baseball étaient le centre de l'existence», selon son biographe Stephen Ambrose ${ }^{17}$. Durant ses années à l'académie militaire de West Point, il pratiqua à haut niveau le football, incitant le New York Times à voir en lui « un des arrières les plus prometteurs de l'Est». Mais une blessure au genou le contraignit à se contenter du rôle d'entraîneur, ce qui le plongea dans un état de profond découragement ${ }^{18}$. Toutefois, «Ike » est surtout connu du grand public pour ses nombreuses parties de golf, notamment sur le parcours d'Augusta (Géorgie), où il s'était fait construire une maison tant il aimait s'y rendre.

\section{[Pour voir les photos, cliquer sur le lien suivant : Eisenhower]}

La mauvaise vue du jeune Harry Truman l'empêcha de pratiquer le sport et lui ferma la porte de West Point. Mais il garda de ses années comme capitaine du 129e régiment d'infanterie, combattant dans les Vosges et en Argonne en 1918, le goût de la marche rapide, qu'il pratiquait, dit-on, chaque matin au lever du jour lorsqu'il était président.

Franklin Roosevelt occupe une place ambigüe dans ce grand récit : piètre joueur de baseball, mais bon manager de l'équipe universitaire d'Harvard, grand nageur et amateur de voile, il dut cesser toute activité sportive en 1921 quand une crise de poliomyélite lui paralysa les membres inférieurs. Contraint au sport thérapeutique (il se fit construire à cet effet une piscine à la Maison Blanche), « FDR » n'en devint pas moins aux yeux des Américains le président le plus engagé pour la cause du sport. Truffant de métaphores sportives ses discours ${ }^{19}$, Roosevelt est entré dans l'histoire

\footnotetext{
15 « (...) if I had to live my life over again, I would have liked to have ended up a sports writer », in Richard Nixon, «Remarks at the Baseball All-Star Reception », 22 juillet 1969, « The American Presidency Project », http:// www.presidency.ucsb.edu/ ws/ ?pid=2137 [lien consulté le 20 octobre 2012]. 16 Richard Crepeau, courriel à l'auteur, 15/10/12; le touch football est une variante du rugby où les joueurs stoppent la progression de l'équipe adverse par un simple contact, sans placage.

${ }_{17}$ Ambrose, cité dans Dave Kindred, « Commentary: Knee Injury Sent Eisenhower Toward D-Day and Presidency », Los Angeles Times, 5juin 1994 ; voir aussi «J FK, le champion de l'Amérique », LÉquipe, 22 novembre 2013.

18 David McCullough, cité à http:// www.pbs.org/ wgbh/americanexperience/features/transcript/ eisenhower-transcript/ [lien consulté le 20 octobre 2012].

19 «Je ne m’attends pas à faire un coup sûr à chaque fois que je prends la batte (...) mais ce que je cherche c'est le plus grand score pour moi et toute l'équipe », (à propos du New Deal), dans FDR,
} 
Peter Marquis, « Les présidents américains et le sport : pouvoirs de l'exercice et exercice du pouvoir, de Theodore Roosevelt à Barack Obama », Histoire@Politique. Politique, culture, société, n²3, mai-août 2014 [en ligne, www.histoire-politique.fr]

sportive comme celui qui a maintenu les championnats de baseball pendant la guerre, malgré la mobilisation, le rationnement, et les risques d'attaque aérienne ${ }^{20}$. Dans sa fameuse lettre donnant le feu vert au Commissaire de la ligue de baseball, il écrivit : « (les travailleurs) doivent avoir la chance de se divertir et de penser à autre chose qu'à leur travail, en ce moment plus que jamais ${ }^{21} »$. Après avoir souligné que le baseball était un divertissement abordable et accessible à tous, il conclut, que « 300 équipes employant 5000 à 6000 joueurs (qui offrent) un moment de détente à plus de 20 millions de compatriotes, » cela était un calcul « pleinement valable ».

\section{[Pour voir les photos, cliquer sur le lien suivant : $\underline{\text { FDR }]}$}

Contrepoint à ce paradigme du «président sportif», les occupants de la Maison Blanche de 1909 à 1933 n'avaient guère d'intérêt pour le sport. On ne garde d'Herbert Hoover que le souvenir de ses années d'entraîneur au lycée et des parties de pêche à la mouche dans sa résidence reculée de Camp Rapidan dans les Blue Ridge Mountains ; Calvin Coolidge, guère enclin aux mondanités, se contentait de marcher seul dans Washington D.C. tôt le matin (pour admirer les vitrines de vêtements pour femme, dit-on), mais, souffrant du dos, il dut y mettre un terme et faire de l'exercice sur un cheval électrique installé à la Maison Blanche pour l'occasion ; quant à Warren Harding, dont on dit qu'il présida le gouvernement le plus corrompu de l'histoire américaine, il préférait recevoir les VIPs sur les parcours de golf ou autour d'une partie de poker bien arrosée.

Woodrow Wilson fait figure d'exception dans cette série de présidents peu sportifs : à 16 ans, il jouait au baseball dans son lycée; puis, à Princeton, il prit les rênes de l'équipe universitaire et obtint de nombreuses victoires grâce à une stratégie de son cru. Une fois à la Maison Blanche, il se rendait souvent dans les stades de baseball et pratiquait le golf régulièrement, même s'il trouvait ce sport « idiot » 22 .

\section{[Pour voir les photos, cliquer sur le lien suivant : Wilson]}

La présidence de Taft, réintègre, quant à elle, le paradigme d'une raréfaction de la pratique sportive dans les années 1910-1930. Le natif de l'Ohio, qui fit campagne en 1908 sans quitter sa maison de Canton (Ohio), eut beau pratiquer le baseball à la faculté de droit de Cincinnati (une anecdote veut même qu'il se soit cassé le bras juste avant que des recruteurs ne lui proposent de signer un contrat semi-professionnel), il marqua surtout la grande histoire des présidents sportifs par son... embonpoint! Même la pratique du golf, qu'il affectionnait pourtant, notamment en compagnie des ploutocrates du Nord-Est, lui était difficile à cause de ses 110 kilos.

[Pour voir les photos, cliquer sur le lien suivant : $\underline{\text { Taft }}]$

\footnotetext{
« Second Fireside Chat », 7 mai 1933, http:// www.presidency.ucsb.edu/ ws/ ?pid=14636 [lien consulté le 8 février 2014].

20 Ron Briley, «Don't Let Hitler (or the Depression) Kill Baseball: Franklin D. Roosevelt and the National Pastime, 1932-1945 », dans Class at Bat, Gender on Deck and Race in the Hole: A Line-Up of Essays on Twentieth Century Culture and America's Game, J efferson (Caroline du Nord), McFarland \& Co, 2003, p. 26.

21 Lettre de Franklin D. Roosevelt à Kenesaw Mountain Landis, 15juillet 1942, FDR Library, http:// www.fdrlibrary.marist.edu/daybyday/resource/january-1942-2/ [lien consulté le 20 octobre 2012].

22 http:// millercenter.org/ president/ wilson/ essays/ biography/ 7 [lien consulté le 20 octobre 2012].
} 
Peter Marquis, « Les présidents américains et le sport : pouvoirs de l'exercice et exercice du pouvoir, de Theodore Roosevelt à Barack Obama », Histoire@Politique. Politique, culture, société, n²3, mai-août 2014 [en ligne, www.histoire-politique.fr]

Dernier de cette liste, mais premier parmi les présidents sportifs aux yeux de nombreux auteurs, Theodore Roosevelt justifierait à lui seul cet article tant sa vie et son oeuvre furent marqués au sceau de ce qu'il appela dans un discours célèbre de 1899 «the strenuous life», qu'on traduira ici par «la vie acharnée» 23 . Les anecdotes sont légions pour faire de «Teddy» le parangon de cette existence compétitive, au contact de la nature, dure à la peine, brutale et virile, du moins selon les standards de la fin de XIX siècle. On retiendra l'image d'un jeune Teddy Roosevelt tour à tour rameur, boxeur, cavalier (on lui prête d'avoir chevauché $1 \mathrm{~h} 30$ non-stop dans une bourrasque de vent et de pluie), alpiniste, mais aussi chasseur et pêcheur. D'ailleurs, il rapporta de son exil volontaire chez les garçons vachers (wranglers) du Dakota du Sud, un tableau de chasse de plus de cent cinquante bêtes, ainsi que trois romans d'aventure ${ }^{24}$.

\section{[Pour voir les photos, cliquer sur le lien suivant : $\underline{\text { T. Roosevelt] }}$}

Une fois installé à la Maison Blanche, à seulement 42 ans (un record), Theodore Roosevelt pratiquait ardemment la lutte, le jujitsu et le tennis (il fit même construire un terrain non loin du Bureau ovale pour y jouer avec ses quatre fils et ses invités). Joignant la théorie à la pratique, celui qui avait commis dans sa jeunesse plusieurs volumes d'histoire navale et d'ornithologie prit souvent la plume pour théoriser cette fameuse strenuous life faite d'utilitarisme, d'endurance, de désintérêt, d'amateurisme et de virilité25. La presse faisait choux gras de sa virilité athlétique et de ses discours édifiants, qui transformaient la Maison Blanche en bully pulpit, tribune morale, d'où Roosevelt menait la nation vers un futur vigoureux. Si l'on ajoute à ce palmarès déjà riche, son expédition victorieuse à la tête du régiment de volontaires des « Rough Riders » pour prendre la colline de San Juan lors de la guerre hispano-américaine de 1898, ainsi que son intervention, controversée, en 1904-1905 pour « sauver » le football universitaire, il émerge une figure de président surhumain (larger than life), mêlant culte de la nature, patriotisme et virilité, figure qui marqua de manière indélébile l'image de la présidence aux yeux du public et de ceux qui lui succéderont ${ }^{26}$.

[Pour voir les photos, cliquer sur le lien suivant : Roosevelt, lutteur métaphorique]

\footnotetext{
23 Theodore Roosevelt, «Speech Before the Hamilton Club, Chicago, April 10, 1899 », dansThe Strenuous Life and Other Essays, Charles Scribner's Sons, 1903, p. 315, en ligne: http://voicesofdemocracy.umd.edu/roosevelt-strenuous-life-1899-speech-text [lien consulté le 20 octobre 2012]. En voici un extrait : « (...) I wish to preach, not the doctrine of ignoble ease, but the doctrine of the strenuous life, the life of toil and effort, of labor and strife; to preach that highest form of success which comes, not to the man who desires mere easy peace, but to the man who does not shrink from danger, from hardship, or from bitter toil (...) ».

24 Ibid. ; sur les œuvres littéraires, voir Gail Bederman, Manliness and Civilization: A Cultural History of Gender and Race in the United States, 1880-1917, Chicago, University of Chicago Press, 1996, p. 170216.

25 Ryan A. Swanson, «"I Never Was a Champion at Anything”: Theodore Roosevelt's Complex and Contradictory Record as America's “Sports President” », J ournal of Sport History, vol. 38, no 3 (2011), p. 430.

26 John S. Watterson, «The BigScrum: How Teddy Roosevelt Saved Football (review) », J ournal of Sport History, vol. 39, no 1 (2012), p. 192-194. ; «largerthan life» est emprunté à Marjolaine Boutet, « Le président des États-Unis, héros de série télévisée. », Le Temps des médias, n¹0, printemps 2008, p. 156.
} 
Peter Marquis, « Les présidents américains et le sport : pouvoirs de l'exercice et exercice du pouvoir, de Theodore Roosevelt à Barack Obama », Histoire@Politique. Politique, culture, société, n²3, mai-août 2014 [en ligne, www.histoire-politique.fr]

Ce tour d'horizon des pratiques sportives des présidents montre donc l'existence d'un paradigme : les dix-neuf occupants de la Maison Blanche de 1901 à 2012 furent tous (ou presque) soit des athlètes de bon niveau, soit des amateurs de sport. Les six contre-exemples furent Taft, Harding, Coolidge, Truman ou, dans une moindre mesure J ohnson et Clinton ${ }^{27}$. Dans la culture populaire, la fonction présidentielle fut donc naturellement associée au statut de sportif. Mais il semble que cela ne suffit point : le président faisait aussi du sport un usage médiatique.

\section{Les usages médiatiques du sport présidentiel}

Premièrement, les présidents aiment à se montrer dans les grands rendez-vous du sport américain, comme le match d'ouverture de la saison de baseball. Ce fut Taft le premier qui, en 1910, à la demande du propriétaire des Washington Senators, inaugura la coutume de lancer la première balle depuis les gradins au joueur qui allait commencer la partie. Cette tradition fut inventée dans les années mêmes où une commission menée par Albert Spalding, ancien sportif devenu propriétaire de club et entrepreneur, prouva, au terme d'une enquête à charge, que le baseball était un sport américain et non britannique, incarnant le génie national « comme deux plus deux font quatre ${ }^{28}$. Après Taft, tous les présidents consentirent à ce rendez-vous devenu, pour Steven Pope, un « rituel patriotique », y compris FDR qui, malgré son invalidité, détient le record de premiers lancers ${ }^{29}$.

\section{[Pour voir les photos, cliquer sur le lien suivant : Obama]}

Depuis quelques années, on voit même les présidents se rendre sur les terrains au cours de la saison de baseball. On pense à Obama saluant la foule et rendant visite aux joueurs lors du All-Star Game de juillet 2009, première sortie sportive après son élection, ou bien à G.W. Bush qui, quelques semaines après les attentats du 11 septembre 2001, se rendit au stade des New York Yankees pour faire le premier lancer du match 3 de la World Series. Soucieux d'exhiber sa virilité, il effectua ce premier lancer depuis le monticule du lanceur, et non depuis les gradins comme c'était l'habitude ${ }^{30}$. Ancien joueur lui-même, Bush lança un strike parfait et reçut de la part des 55000 spectateurs un tonnerre d'applaudissements accompagnés des cris «USA, USA, USA »31.

\footnotetext{
${ }^{27}$ Les archives ne renseignent sur aucune activité sportive chez le jeune Lyndon J ohnson ; de plus, une fois président, il préférait se détendre dans son ranch avec ses chevaux que sur les terrains de golf, sauf à de très rares occasions, voir Scott Simon, «Among The Games Presidents Play...», op. cit. Quant à Clinton, au lycée, il s'intéressait davantage à la musique (saxophone) qu'au sport; puis, à la Maison Blanche, il pratiquait certes le golf, mais sans guère se soucier des règles, au point que certains commentateurs tracèrent un parallèle entre son laxisme sportif et ses relations extra-maritales.

28 Cité in Peter Levine, A. G. Spalding and the Rise of Baseball, the Promise of American Sport, New York, Oxford University Press, 1986, p. 118. Sur baseball et présidence, George Rable, « Patriotism, Platitudes and Politics: Baseball and the American Presidency », Presidential Studies Quarterly, 1989, p. 363-372.

29 Steven W. Pope, Patriotic Games: Sporting Traditions in the American Imagination, 1876-1926, $2^{\mathrm{e}}$ ed., Knoxville, University of Tennessee Press, 2007, p. 75. Pour FDR, Nelson Murry, « Presidents and Opening Day in Baseball », dans Nelson Murry (dir.), American Sports: A History of Icons, Idols and Ideas, ABC-Clio, 2013.

30 Bush lança du monticule sur les conseils du joueur des Yankees Derek J eter, « Prologue: Pieces of History, 9/ 11: The World Series and a President's pitch », http:// blogs.archives.gov/ prologue/ ?p=6890, [lien consulté le 20 octobre 2012].

31 Une vidéo de ce premier lancer est disponible
àhttp:// mlb.mlb.com/ video/ play.jsp?content id=12927859 [lien consultéle 10 février 2014].
} 
Peter Marquis, « Les présidents américains et le sport : pouvoirs de l'exercice et exercice du pouvoir, de Theodore Roosevelt à Barack Obama », Histoire@Politique. Politique, culture, société, n²3, mai-août 2014 [en ligne, www.histoire-politique.fr]

\section{[Pour visionner la vidéo, cliquer sur le lien suivant : vidéo Bush J r]}

La diffusion de l'hymne américain et le salut aux soldats avant chaque match de championnat achèvent de faire du baseball le sport national par excellence, religion civile à laquelle les présidents doivent s'associer ${ }^{32}$. Leur présence est aussi de rigueur au traditionnel match de football opposant l'Armée de terre à la Marine (ArmyNavy Game), où le président change de côté à la mi-temps pour symboliser son attachement aux deux corps. Depuis peu, les présidents font même des apparitions publiques à la finale du championnat universitaire de basket (NCAA) ou à la course automobile « Daytona 500 ».

Deuxièmement, il est devenu habituel que les présidents s'affichent avec des célébrités du monde du sport : Ronald Reagan le fit plus de quarante fois durant ses deux mandats, avec des vedettes telles qu'Arthur Ashe, Patrick Ewing, et Wayne Gretzky, ou les légendes J oe Di Maggio et Mohammed Ali ${ }^{33}$; quant à Bill Clinton, il invita en 2011 Michael J ordan pour une partie de golf très médiatisée.

\section{[Pour voir les photos, cliquer sur les liens suivants : Reagan et Ali et Clinton et Jordan]}

Troisièmement, les présidents aiment afficher leur culture sportive en public, afin d'affirmer qu'ils sont des Américains ordinaires. Nixon, par exemple, lors de sa campagne pour le Congrès en 1946 publia un tract précisant qu'il avait travaillésuccessivement « dans un entrepôt de conditionnement de fruits, comme pompiste dans une station essence» et, je cite l'historien Robert Collins, " pour parachever son portrait d'homme ordinaire en convoquant le plus large dénominateur commun », qu'il avait «joué au football à l'université ${ }^{34}$ ». Puisqu'une grande partie des Américains fréquentent des écoles où les sports sont pratiqués de manière compétitive, Nixon espérait que les électeurs identifient en lui un Américain ordinaire. Cette stratégie est devenue aujourd'hui un trope aussi incontournable que le rappel patriotique de l'expérience sous les drapeaux, crucial pour Truman, Kennedy, ou le candidat McCain. Les universitaires Moore et Dewberry affirment même que la participation sportive remplace l'expérience militaire pour les présidents comme Clinton, BushJr., ou Obama, dont la particularité est de n'avoir jamais servi sous les drapeaux ${ }^{35}$.

Barack Obama, souvent accusé d'être élitiste, hautain, voire né à l'étranger (ce qui lui ôterait le droit d'être président), a très souvent recours au thème du sport à des fins politiciennes ${ }^{36}$. En mars 2012, il consacra trente minutes à Bill Simmons, étoile montante du journalisme sportif, afin d'évoquer divers sujets, que certains

\footnotetext{
32 J oshua Fleer, «The Church of Baseball and the U.S. Presidency », NINE: A J ournal of Baseball History and Culture, vol. 16, no 1(2007), p. 51-61.

$33 \mathrm{La}$ liste intégrale est à http://www.reagan.utexas.edu/archives/photographs/sports.html [lien consultéle 8 février 2014].

34 Tract de campagne pour Nixon, 1946, cité dans Robert M. Collins, « Richard M. Nixon : The Psychic, Political, and Moral Uses of Sport », J ournal of Sport History, vol. 10, n 2 (1983), p. 80.

${ }^{35}$ Moore A. J . et Dewberry D., « The Masculine Image of Presidents As Sporting Figures: A Public

Relations Perspective », SAGE Open, 2012, vol. 2, n 3, p. 2.

${ }^{36}$ Russ Crawford, « Bowling, Basketball, BCS, Baseball, and Birdies: Obama's Use of Sport to Connect », LA Progressive, http:// www.laprogressive.com/bowling-basketball-bcs-baseball-and-birdies-obamasuse-of-sport-to-connect/ [lien consulté le 20 octobre 2012]. Il remarque : « for the sheer frequency of his sports appearances, pronoucements and use however, Obama has set a pace that is beyond anything his predecessors did in office ».
} 
Peter Marquis, « Les présidents américains et le sport : pouvoirs de l'exercice et exercice du pouvoir, de Theodore Roosevelt à Barack Obama », Histoire@Politique. Politique, culture, société, n²3, mai-août 2014 [en ligne, www.histoire-politique.fr]

considéreraient triviaux de la part du président des États-Unis (son pronostic pour le championnat universitaire, le basketteur sino-américain J érémy Lin, la qualité de l'abonnement de la télévision de la Maison Blanche aux chaînes sportives, etc.) ${ }^{37}$. En réalité, passer chez Bill Simmons constituait une entrée en campagne: Obama cherchait non seulement à faire taire les accusations d'élitisme, mais aussi à séduire les 18-35 ans, auditoire principal de Bill Simmons et segment de l'électorat qui le fit élire en 2008, mais qui risquait de lui manquer en $2012^{38}$.

\section{Des analyses qui renforcent la figure du « président sportif »}

Le dernier élément conférant au couple sport/président un rapport de consubstantialité se situe dans les analyses régulièrement offertes pour expliquer ce phénomène. Pour résumer les thèses les plus fréquentes, le président pratiquerait le sport et s'associerait à des évènement sportifs car (1) c'est un moment de détente au sein d'un emploi du temps surchargé ; (2) c'est, en termes de relations publiques, un investissement sûr présentant peu de risques de retombées négatives ; (3) c'est un lieu de sociabilité propice à l'entretien d'un réseau de connaissances, utile pour influencer, négocier, et connaître la « vraie personnalité » de ses partenaires et de ses adversaires ${ }^{39}$; (4) c'est une bonne école pour former le tempérament et apprendre à gagner, perdre, mener, obéir, s'intégrer dans une équipe, lire le jeu de l'adversaire, etc., bref l'antichambre idéale au jeu politique ; (5) c'est une fenêtre ouverte sur les goûts intimes du président qui révélerait son identité héritée ou choisie ${ }^{40}$; (6) défendre la cause des sports permet de disséminer un discours sur l'identité nationale sans avoir recours aux discours exceptionnaliste ou nationaliste ${ }^{41}$; (7) pour les psychohistoriens, le sport révèlerait les névroses des hommes d'État: Robert Collins, par exemple, estime que Nixon fut mené à sa perte par son incapacité à se détacher d'une «cosmographie morale » héritée du football, qui considère toute chose en termes de compétition, de victoire/défaite, de «nous contre eux » ${ }^{42}$; (8) enfin, pour ses détracteurs, l'omniprésence du sport dans la vie du président

37 « BS Report: Barack Obama», Grantland, 30 avril 2012, extraits vidéo et script disponibles à http:// www.grantland.com/blog/the-triangle/post/_id/18687/b-s-report-barack-obama [lien consulté le 20 octobre 2012].

38 Voir la citation «Quand Obama parle sport, il montre à l'Amérique son acte de naissance », dans Bryan Curtis $\quad$ "Barack/Nixon», 18 mai 2012, http:// www.grantland.com/story/ / id/ 7942866/the-eerie-similarities-barack-obama-richard-nixontwo-our-biggest-sports-fans-chief [lien consulté le 20 octobre 2012].

${ }^{39}$ Voir la citation du President de la chamber basse, J ohn Boehner : « When you start trying to hit that little white ball you can't be somebody that you're not, all of you shows up », citédans Scott Simon, «Among The Games Presidents Play, There's Also Golf», NPR News (NPR, 18 juin 2011), http:// m.npr.org/news/ Politics/ 137257601 [lien consulté le 20 octobre 2012].

40 On pense au choix du jeune Obama d'exceller dans le basket afin de « passer pour noir » auprès de ses comparses du lycée Punahou de Honolulu, anecdote citée dans PapNdiaye, « Le style d'Obama », blog, Elections américaines vues par Pap Ndiaye, 9 novembre 2008, http://electionsamerica.canalblog.com/archives/2008/11/09/11294480.html. [lien consulté le 20 octobre 2012].

41 On pense ici aux craintes d’Eisenhower (puis de Kennedy) de voir leur pays dépassé par les compétences athlétiques des Russes: Dwight Eisenhower, «Executive Order 10772 », 30 juin 1958, http:// www.presidency.ucsb.edu/ ws/ ?pid=60628 [lien consulté le 3 juin 2014]. ; J ohn Kennedy, « The Soft American », Sports Illustrated, 26 décembre 1960 ; mais aussi de Clinton utilisant le retour de la World Series en 1995 (après un an de grève) pour parler du base-ball comme lien entre les générations et les individus (William Clinton, «The President's Radio Address », 21 octobre 1995, en ligne, http:// www.presidency.ucsb.edu/ ws/index.php?pid=50679\&st=\&st1 [lien consulté le 20 octobre 2012]. 42 Robert M. Collins, « Richard M. Nixon: The Psychic, ..»», op. cit., p. 84. 
Peter Marquis, « Les présidents américains et le sport : pouvoirs de l'exercice et exercice du pouvoir, de Theodore Roosevelt à Barack Obama », Histoire@Politique. Politique, culture, société, n²3, mai-août 2014 [en ligne, www.histoire-politique.fr]

serait la preuve ultime que la démocratie américaine est corrompue, gangrénée par l'argent des affaires et des ploutocrates, pervertie par l'éthique capitaliste de la performance et du patriotisme sectaire ${ }^{43}$. À cet égard, la manière dont G. W. Bush est parvenu à la Maison Blanche grâce à l'argent du pétrole et du sport suscita beaucoup de controverses ${ }^{44}$.

Ce répertoire d'usages sociaux de la culture sportive atteste que la culture sportive est tel un devoir dont il faut s'acquitter pour avoir le permis de présider. On s'étonnera, depuis notre lorgnette française, que les auteurs américains n'aient pas plus souligné la place du sport dans l'éducation des élites, comme c'est le cas en Europe (compétitions entre public schools britanniques ou critériums inter-IEP en France). Puisqu'en Europe les élites politiques viennent toutes ou presque du même sérail (Oxbridge, ENA, etc.), on est en droit de se demander si aux États-Unis le passage par l'université (notamment de l'Ivy League) garantissant la découverte de la sociabilité sportive universitaire, ne serait pas un pré-requis à quiconque brigue la plus haute fonction de l'État. Toutefois, si l'on examine la situation de plus près, on constate que la thèse de la consubstantialité du sport à la présidence fut exagérée et mérite un réexamen approfondi dans le but de souligner la complexité des rapports entre la culture sportive des présidents et l'usage éminemment politique de celle-ci.

\section{Réexaminer le « président sportif »}

\section{Corps fragiles}

L'histoire conventionnelle se montre particulièrement silencieuse sur un point crucial, à savoir la relative mauvaise santé physique des présidents. On sera étonné de constater que sept des dix-neuf présidents étudiés (soit 37\%) présentaient avant leurs 30 ans des problèmes de santé les rendant inaptes à la pratique sportive ${ }^{45}$. Theodore Roosevelt, quintessence du président athlétique, souffrait dans sa jeunesse d'asthme et d'une constitution chétive ; Taft était en surpoids ; Wilson souffrait d'une mauvaise vue, de dyslexie et de troubles neurologiques ; Truman était myope ; FDR, même avant sa crise de polio, était mal à l'aise pour jouer au baseball à l'institution privée Groton. Même. Mais le cas le plus spectaculaire reste celui de J ohn Kennedy : son enfance fut scandée par des affections à répétition (toux, scarlatine, rougeole, jaunisse), puis, adulte, il contracta une infection de l'urètre, la malaria, et, surtout, la maladie d'Addison, maladie endocrinienne débilitante, provoquant chez lui des douleurs dorsales le forçant à se soigner à la cortisone jour et nuit. Tous ces exemples mettent à mal le mythe d'une présidence naturellement athlétique.

\footnotetext{
43 Pour uneapprocheglobale: George Harvey Sage, Power and Ideology in American Sport: A Critical Perspective, Champaign (Illinois), Human Kinetics, 1998, chap. 9, « The Professional Team Sports Industry », p. 189 et sq. ; pour un exemplerécent : RosKrasny, « Romney Takes a Swing at Obama Golf Habit », blogs.reuters.com, 7 décembre 2011, [lien consultéle 8 février 2014].

44 En 1988, G. W. Bush devint copropriétaire des Texas Rangers, en empruntant de l'argent à ses partenaires du secteur pétrolier ; du fait de sa notoriété (son père était alors vice-président), il obtint de la mairie d'Arlington qu'elle finance avec l'argent des contribuables une grande partie du nouveau stade des Rangers. L'équipe prospéra et en 1998, Bush vendit ses parts, réalisant un profit de plus de 14 millions de dollars, voir Dave Zirin, Bad Sports: How Owners Are Ruining the GamesWe Love, Scribner, New York, 2010, p. 41-42.

45 Statistiques personnelles réalisées à partir de plusieurs sources, dont principalement John S. Watterson, The Games..., op. cit. ; et « American President: A Reference Resource», Miller Center, op. cit.
} 
Peter Marquis, « Les présidents américains et le sport : pouvoirs de l'exercice et exercice du pouvoir, de Theodore Roosevelt à Barack Obama », Histoire@Politique. Politique, culture, société, n²3, mai-août 2014 [en ligne, www.histoire-politique.fr]

De plus, que penser de ces photographies peu flatteuses où le chef de l'exécutif est montré transpirant, haletant, souffrant en short et en baskets, le regard rendu hagard par l'effort ${ }^{46}$ ? Comment l'aura du président largerthan life peut-elle survivre à ce portrait réaliste du président en homme ordinaire, malade, épuisé, ou maladroit (on pense à Carter trébuchant devant les caméras lors d'un footing) ?

\section{[Pour voir les photos, cliquer sur le lien suivant : Carter]}

\section{Révisions universitaires}

L'histoire des rapports entre chaque président et le sport ne saurait se réduire à quelques raccourcis, aussi spectaculaires ou patriotiques soient-ils. Des universitaires commencent à envisager une complexification de ces rapports. Ryan Swanson, par exemple, soutient que Theodore Roosevelt ne fut pas le «sauveur » du football et chantre de la vie athlétique ${ }^{47}$. Il connut des revers politiques et symboliques à au moins quatre niveaux. Tout d'abord, il échoua à limiter l'impact de l'argent sur le monde de la boxe ; puis en 1904-1905, alors qu'un rapport alarmant fit état de dixhuit morts sur les terrains de football universitaire à cause de la violence des contacts, il ne parvint pas à convaincre les présidents d'université de suspendre les compétitions. Au terme d'un long bras de fer avec Charles Jones, président d'Harvard, le président des États-Unis n'obtint pas mieux qu'un compromis prévoyant une interruption temporaire ${ }^{48}$. Troisièmement, dans sa «doctrine athlétique », qu'il théorisa en $1919^{49}$, il prônait la pratique du sport à des fins de développement du tempérament et pour l'édification d'une nation robuste et morale. Or ces premières années du XX ${ }^{\mathrm{e}}$ siècle virent les signes opposés se développer : les nouveaux stades urbains accueillaient des millions de spectateurs qui observaient le sport plutôt qu'ils n'y participaient. Pis encore, c'était bien le baseball, sport qu'il jugeait réservé aux « petites natures » (mollycoddles) ${ }^{50}$, qui attire les foules (plus de 7 millions de spectateurs en 1908, deux fois plus qu'en 190351), et non les sports de contact comme la boxe. Enfin, rares sont les sports dominants des années 1900-1920 qui restent fidèles au précepte de l'amateurisme; certains, comme l'hippisme, recrutent même leur public parmi les parieurs et les membres de la pègre ${ }^{52}$. Au final, «TR» ne semble pas en phase avec son époque, comme si sa culture sportive s'inspirait plus de la vieille Europe des public schools et de Pierre de Coubertin (avec qui il correspondait), que de l'essor d'un sport de masse professionnel inextricablement intégré au capitalisme industriel.

\section{Des fiascos communicationnels}

\footnotetext{
${ }^{46}$ Pour Carter et Ford, voir http:// cryptome.org/ eyeball/prezsec/ prezsec-eyeball5.htm [lien consulté le 8 février 2014] ; pour G. H. W. Bush et Clinton, voir http:// eowynchallenge.blogspot.fr/2011/02/inhonor-of-presidents-day.html ; [lien consultéle 8 février 2014].

${ }^{47}$ Ryan A. Swanson, « Never Was a Champion... », op. cit., p. 436-437.

48 Cette interruption devait durer le temps d'étudier les propositions d'aménagement des règles soumises par les proches de Roosevelt, ibid., p. 438.

49 « Roosevelt as Sportsman », Boston Globe, 5 février 1919, cité dans ibid., p. 443 n.

50 Propos de sa fille, Alice (Roosevelt) Longworth, cités in ibid., p. 443.

51 Steven A. Riess, Touching Base: Professional Baseball and American Culture in the Progressive Era, Urbana, University of Illinois Press, 1999, p. 5.

52 Steven A. Riess, « The American J ockey, 1865-1910 », Transatlantica. Revue d'études américaines, no 2, juin 2012, paragr. 2, http:// transatlantica.revues.org/ 5480, [lien consulté le 20 octobre 2012].
} 
Peter Marquis, « Les présidents américains et le sport : pouvoirs de l'exercice et exercice du pouvoir, de Theodore Roosevelt à Barack Obama », Histoire@Politique. Politique, culture, société, n²3, mai-août 2014 [en ligne, www.histoire-politique.fr]

Il est admis dans les cercles politiques que présenter le président comme « fan » lui garantirait la sympathie du public qui identifierait en lui un homme aux goûts ordinaires, proche des préoccupations et des plaisirs de ses administrés. Mais l'histoire populaire des présidents sportifs néglige souvent les nombreux exemples où cette stratégie de relations publiques conduit à un fiasco. Herbert Hoover en fit le premier les frais quand, en 1931, il souhaita exploiter l'intérêt du public américain pour le baseball, malgré la crise économique qui le frappait ${ }^{53}$. Il se rendit à la World Series opposant Philadelphie à St Louis pour faire le premier lancer, mais au lieu d'applaudir Hoover, les spectateurs le huèrent sous les cris répétés de «wewantbeer ». En effet, le président s'était opposé à une abrogation du XVIII amendement, interdisant la vente et la distribution d'alcool.

Eisenhower essuya également beaucoup de critiques quant au temps qu'il passait sur les parcours de golf; il fut estimé que ce loisir l'occupa 365jours sur l'ensemble de son mandat! Les Démocrates firent de cette passion chronophage le symbole d'une présidence qui manquait d'engagement et demeurait désintéressée des préoccupations de son temps, comme la résolution de la guerre de Corée, ou l'application de l'arrêt deségrégationniste Brown versus Board of Education. Le regard porté par les Démocrates sur la pratique sportive d'Eisenhower était tellement négatif que son successeur Kennedy, pourtant réputé avoir le meilleur swing de tous les présidents, s'évertuait à jouer au golf loin du regard des journalistes, voire en soirée, pour ne pas s'exposer à la même critique.

La troisième victime de ce retour de bâton communicationnel fut Richard Nixon qui en 1971, en pleine guerre du Vietnam, alors que des étudiants passaient la nuit au Lincoln Memorialen préparatifs d'une manifestation s'indignant contre la mort de quatre manifestants à Kent State University, sortit en pleine nuit et décida d'aller à leur rencontre. Après avoir évoqué plusieurs sujets, il entama la conversation avec une jeune femme en lui demandant d'où elle venait et, à la grande surprise des manifestants, il leur parla de l'équipe de football de cette université (en l'occurrence Syracuse). Un étudiant présent nota plus tard que cette remarque avait fini de le convaincre de l'incapacité de Nixon à comprendre la jeunesse en rébellion ${ }^{54}$. De plus, le football universitaire représentait pour la Nouvelle gauche une excroissance odieuse du capitalisme, obsédé par la performance, la victoire, la fierté arbitrairement fondée sur une appartenance identitaire rappelant par trop le nationalisme qui avait justifié la guerre au Vietnam ${ }^{55}$. Alors que Nixon voulait se rapprocher de ces jeunes qui ne le comprenaient pas, il ne fit qu'agrandir le fossé les séparant.

Dernier exemple plus récent, John Kerry, candidat démocrate en 2004, voulut affirmer son appartenance à la culture du Massachusetts en s'inventant une identité de supporteur des Red Sox de Boston, grande équipe de baseball, génératrice d'un supportérisme ostentatoire connu dans tout le pays. Mais Kerry commit une gaffe

\footnotetext{
53 Hoover s'expliquaa posteriori «I felt my presence at a sporting event might be a gesture of reassurance in a country suffering from a severe case of the jitters », dans John S. Watterson, The Games..., op. cit., p. 135.

54 Voir les propos d'un étudiant de Syracuse : « I hope it was because he was tired, but most of what he was saying was absurd. Here, we had come from a university that's completely uptight, on strike, and when we told him where we were from, he talked about the football team », en ligne à http:/ / www.theatlantic.com/ politics/ archive/ 2011/ 11/i-am-not-a-kook-richard-nixons-bizarre-visit-tothe-lincoln-memorial/248443/ [lien consulté le 20 octobre 2012].

55 Richard M. Collins, « Richard M. Nixon...», op. cit., p. 31.
} 
Peter Marquis, « Les présidents américains et le sport : pouvoirs de l'exercice et exercice du pouvoir, de Theodore Roosevelt à Barack Obama », Histoire@Politique. Politique, culture, société, n²3, mai-août 2014 [en ligne, www.histoire-politique.fr]

impardonnable aux yeux du public en affirmant que son joueur préféré était l'imaginaire « Manny Ortez », amalgame malheureux des noms de deux joueurs bien réels ${ }^{56}$. Alors que Kerry souffrait déjà d'un déficit de popularité auprès des Américains moyens (avait-il vraiment combattu au Vietnam ? pourquoi était-il si proche des Français, qui refusaient de s'engager en Irak ?), cette fabrication ratée d'une persona sportive acheva de le ranger dans le camp des élites inauthentiques.

\section{Le contre-exemple de l'olympisme américain}

Dernier point, même si l'idéal olympique prévoit que les Jeux ne soient jamais utilisés dans un dessein politique, il serait naïf d'imaginer que chaque nation ne cherchât pas à obtenir le plus grand nombre de médailles possible. Le CIO ne délivre pas le classement des médailles, mais les journaux de chaque pays le font, dans un souci de compétition et de recherche de supériorité. De plus, les sommes dépensées pour la préparation des athlètes attestent que les J eux sont un enjeu de politique internationale pour les nations participantes. D'ailleurs, l'URSS, la RDA et d'autres ont cherché pendant la guerre froide à instrumentaliser les réussites des athlètes pour renforcer le soutien populaire au régime. Du côté américain, les historiens ont prouvé que la guerre froide fut aussi menée sur le front culturel : l'United States Information Agency, Hollywood, les programmes Fulbright, etc., constituèrent une continuation de la guerre par le « soft power ».

De manière surprenante, le sport est un point relativement aveugle de cette politique d'endiguement culturel ${ }^{57}$. Certaines voix se sont bel et bien élevées en faveur d'une équipe olympique américaine dominante. Robert Kennedy, dépité par le maigre nombre de médailles ramenées de Rome, poussa Lyndon Johnson à plus de volontarisme pour réorganiser le mouvement olympique américain ${ }^{58}$. J ohnson fut en particulier encouragé à régler le différend entre deux organisations de sport amateur concurrentes et à utiliser son Conseil présidentiel pour la bonne santé de la jeunesse à des fins de préparation olympique. En vain. Non seulement le budget du Département d'Etat (la seule section du gouvernement fédéral chargée des sports amateurs) déclina drastiquement, en raison des dépenses consenties pour la guerre du Vietnam, mais encore l'exécutif américain n'avait ni coutume ni vocation à intervenir sur un sujet mineur comme le sport, réservé aux juridictions inférieures que sont les États et les communes. Il fallut attendre le gouvernement de Ford pour que soit créée la «Commission présidentielle sur les sports olympiques », rassemblant tous les organes jusqu'alors actifs de manière disparate $\gg 59$.

Dans l'histoire de ce rendez-vous manqué avec un olympisme au service de la nation, les années J ohnson ne sont pas une exception. En fait, dès les J eux de 1904, pourtant organisés à St Louis (Missouri), aucun président américain ne se rendit sur les lieux

\footnotetext{
${ }^{56}$ J oshua Fleer, « The Church of Baseball..»», op. cit., p. 55.

57 Quelques ouvrages défendent la thèse inverse en s'appuyant sur les «tournées mondiales » des champions de baseball après-guerre, l'envoi de J esse Owens comme « ambassadeur de bonne volonté » en Asie, ou la création des «J eux de la bonne volonté » (Goodwill Games) en 1980, voir par exemple Russ Crawford, The Use of Sports to Promote the American Way of Life During the Cold War: Cultural Propaganda, 1946-1963, Lewiston, NY, Edwin MellenPress, 2008; voir aussi Jérôme Gygax, Olympisme et guerre froide culturelle: Le prix de la victoire américaine, Paris, l’Harmattan, 2012.

58 Thomas Hunt, «American Sport Policy and the Cultural Cold War: The Lyndon B. Johnson Presidential Years », J ournal of Sport History, autumn 2006, p. 274.

59 Olivia B. Waxman, «A Brief History of U.S. Presidents and the Olympics », Time, 27juillet 2012, http:// swampland.time.com/ 2012/ 07/ 27/a-brief-history-of-u-s-presidents-and-the-olympics/ \#all., [lien consultéle 20 octobre 2012].
} 
Peter Marquis, « Les présidents américains et le sport : pouvoirs de l'exercice et exercice du pouvoir, de Theodore Roosevelt à Barack Obama », Histoire@Politique. Politique, culture, société, n²3, mai-août 2014 [en ligne, www.histoire-politique.fr]

des compétitions. Il fallut attendre le boycott des J eux de Moscou en 1980, impulsé par Carter en représailles à l'invasion soviétique de l'Afghanistan, pour que les olympiades occupent le devant de la politique présidentielle américaine ${ }^{60}$. Ce fut seulement en 1984 que Reagan devint le premier président à assister aux J eux, mais ils eurent lieu pendant une année électorale et à Los Angeles, son bastion historique. En 2008, Bush fit le voyage à Pékin, devenant le premier président à se déplacer officiellement pour ce motif ; toutefois, on ne peut affirmer qu'il ait inauguré une tradition, puisqu'Obama ne se rendit pas à Londres en 2012, préférant déléguer cette tâche à son épouse Michelle, qui profita de l'occasion pour asseoir son image de Première dame attachée à la bonne santé physique et au combat contre l'obésitéc1.

Ces quatre réexamens permettent de battre en brèche le mythe d'une essence du " président sportif » et de démontrer qu'une approche approfondie s'impose si l'on veut éviter de pérenniser des conclusions qui sont en fait le fruit d'un calcul politique, à savoir créer l'image du président vigoureux, du président en phase avec les mours de son temps, du président fan de sport, et du président utilisant le sport olympique pour asseoir la supériorité américaine dans le monde. Mais la culture sportive ne se réduit pas aux usages publics du sport ; elle agit également au niveau intime et peut à ce titre être étudiée comme une facette de l'exercice du pouvoir.

\section{Le sport présidentiel dans la pratique de l'exécutif}

Qu'apporte le sport dans la formation d'un homme d'État? Difficile de répondre sans tomber dans deux travers, qui d'ailleurs s'entrecroisent : la psychologie déterministe ( « sa pratique du sport l'a naturellement formé à l'art de la politique »), ou l'illusion rétrospective ( «c'est au moment où il entraîne telle équipe qu'il forge son tempérament de chef »). Ces deux travers ont en commun de prêter au sport des vertus essentialisées, comme le leadership, la soif de vaincre, l'esprit d'équipe, le fairplay, etc. Les tenants de cette interprétation vont même jusqu'à évoquer deux types de présidents : les présidents-footballeurs, soucieux du collectif, face aux présidentsgolfeurs, plus individualistes ${ }^{62}$. Cela n'est guère convaincant, car il existe autant de manière de pratiquer un sport qu'il y a de sportifs. Cette mise en garde ne cherche pas à minimiser le rôle du sport dans la formation des futurs présidents, mais à souligner qu'il fut un facteur parmi des dizaines d'autres. Notre ambition ici est plutôt de proposer des hypothèses sur les domaines et les moyens par lesquels il peut façonner la pratique du pouvoir.

\section{Le sport dans le quotidien de l'exécutif}

\footnotetext{
60 Pour unaperçutrès critique de l'action de Carter, voir Nicholas Evan Sarantakes, Dropping the Torch: J immy Carter, the Olympic Boycott, and the Cold War, New York, Cambridge University Press, 2010.

61 U.S. Embassy in London, «Michelle Obama Leads U.S. Delegation to London Olympics », 27juillet 2012, http://london.usembassy.gov/gb187.html [lien consulté le 20 octobre 2012] ; Barack Obama invita l'intégralité de «Team USA à la Maison Blanche en septembre 2012, http://www.whitehouse.gov/blog/2012/09/14/team-usa-visits-white-house [lien consulté le 20 octobre 2012$]$.

62 J ohn S. Watterson, « National Press Club Book Fair», entretien à CSPAN, 15 novembre 2006, http://www.c-spanvideo.org/program/TheGam [lien consulté le 20 octobre 2012] ; la typologie individualiste/ collectif (one man player vs. team player) est une arme politique depuis la campagne de 1912 opposant Taft à Wilson), Steven Pope, PatrioticGames, op. cit., p. 75.
} 
Peter Marquis, « Les présidents américains et le sport : pouvoirs de l'exercice et exercice du pouvoir, de Theodore Roosevelt à Barack Obama », Histoire@Politique. Politique, culture, société, n²3, mai-août 2014 [en ligne, www.histoire-politique.fr]

Quelle place joue le sport dans le quotidien des présidents, donc dans l'intime de l'exercice du pouvoir? Trois anecdotes nous renseignent à ce sujet, même si aucune interprétation univoque ne peut être dégagée. Premièrement, à l'été 1909, le président Taft préfère jouer au golf plutôt que d'arbitrer le débat interne au Parti républicain sur les tarifs douaniers ; il justifia même cette attitude en disant: « Et maintenant, je veux montrer mon mépris pour un exécutif interventionniste en passant l'après-midi sur les parcours de golf $\gg 63$. Quelques semaines plus tard, la loi Payne-Aldrich, issue des ces débats, fut votée, déclenchant la colère et l'éloignement des progressistes qui avaient soutenu jusque-là le président. Ici, la partie de golf est pleinement assumée comme un ailleurs de la politique, une tactique dilatoire pour ne pas prendre part aux négociations, bref un moyen de tracer une ligne de démarcation entre ce qui ressort de la mission présidentielle et ce qui n'en ressort pas.

Deuxième moment, Woodrow Wilson joua au golf le 3 avril 1917, jour où il adressa au Congrès son message annonçant que les États-Unis entraient en guerre contre l'Allemagne; au fil du mois d'avril, premier mois de la guerre, il joua même douze fois, soit plus d'une fois tous les trois jours. Il se peut que le calme du golf ait pu être le pendant de l'activité politique, son envers plus serein et solitaire. Le président y préparait sa politique en faisant tout autre chose que de la politique ${ }^{64}$.

La troisième anecdote, tirée d'un long reportage dans Vanity Fair sur « le style d'Obama », interroge le rôle du basket dans la façon dont le $44^{\mathrm{e}}$ président des ÉtatsUnis pense l'exercice du pouvoir. Malgré son emploi du temps serré, il pratique régulièrement ce sport qu'il affectionne depuis le lycée et dans lequel il montre de l'aisance, malgré ses 51 ans $^{65}$. Pour lui, la pratique régulière du basket ne constitue pas une échappatoire, mais une école à la prise de décision, comme le montre le récit suivant.

Un dimanche matin de septembre 2012, il se rend avec une escorte réduite aux bureaux du FBI où l'attendent dans l'un des gymnases une douzaine de joueurs « d'environ 25 ans mesurant 2 mètres et ayant tous joué dans les équipes de leur université66 ». La partie commence et le journaliste de Vanity Fair s'étonne : «ce n'est pas un match pour le plaisir ; tous ceux qui sont là jouent pour gagner », y compris le président à qui personne ne réserve un traitement de faveur. « $\mathrm{Si}$ tu y vas mollo avec lui », explique un joueur, «il ne te réinvite pas ». Obama a d'ailleurs perdu une dent et dut recevoir 12 points de suture à la suite d'une de ces parties ; de plus, son jeu n'est pas assez rapide donc il est vite dominé. Comment comprendre dès lors qu'il s'impose un tel désagrément, alors qu'il pourrait aisément briller auprès de joueurs de son âge? Le journaliste estime qu'Obama aime devenir le temps d'un

\footnotetext{
63 « And now I want to show my scorn for further mediation [of the executive branch] by spending the afternoon on the golf links », cite dans J ohn S. Watterson, The Games...,op. cit., p. 75.

64 Près de soixante-dix ans plus tard, un conseiller de Reagan fournit à ceux qui critiquaient les absences et vacances à répétition du président une justification que Wilson aurait pu prendre à son compte : « [le président n'est pas fainéant] ; nous avons simplement remarqué qu'il était plus efficace quand il était reposé et libre dans son emploi du temps, "Ronald Reagan's Family Life», Miller Center, http:// millercenter.org/president/ reagan/ essays/ biography/ 7 [lien consulté le 20 octobre 2012

65 Obama est le premier occupant de la Maison Blanche à revendiquer le basket comme son sport favori ; avant lui, seul Clinton avait gardé de ses années d'assistant coach à Yale une fine connaissance du jeu qui ne lassait pas d'impressionner ces collaborateurs, voir John S. Watterson, « National Press Club Book Fair », op. cit. Concernant les liens entre basket, identité afro-américaine et mobilisation politique, voir Nicolas Martin-Breteau, «Un "sport noir" ? Le basket-ball et la communauté africaine-américaine », Transatlantica, $\mathrm{n}^{\circ}$ 2, 2011, http:// transatlantica.revues.org/ 5469 [lien consulté le 20 octobre 2012].

66 Michael Lewis, « Obama’s Way », Vanity Fair, 2 octobre 2012.
} 
Peter Marquis, « Les présidents américains et le sport : pouvoirs de l'exercice et exercice du pouvoir, de Theodore Roosevelt à Barack Obama », Histoire@Politique. Politique, culture, société, n²3, mai-août 2014 [en ligne, www.histoire-politique.fr]

match un joueur ordinaire, qui contribue, sans briller, au succès de l'équipe. Mais on peut aussi interpréter cette recherche de compétitivité et de mise en danger comme un entraînement au métier de président. Le parallèle entre le sport et le processus de décision politique est manifeste dans l'opinion que se fait Obama de ses chances de réussite dans son travail de président : « chaque décision que je prends » dit-il, « a 30 ou $40 \%$ de chance de ne pas fonctionner », tel un lancer vers le panier ou une frappe avec une batte, serait-on tenter d'ajouter ${ }^{67}$.

En plus de cette préparation à la probabilité de l'échec, Obama consacre une heure chaque matin à un entraînement physique. Pour justifier cette pratique, il explique : « si tu ne t'entraînes pas, un jour ou l'autre tu vas t'effondrer », soulignant que le sport est pour lui un entraînement à la performance mentale et physique exigée par le jeu politique ${ }^{68}$. Hasard de la langue ou vérité des mots, «performance» et «jeu » sont deux termes qui appartiennent aussi au vocabulaire des arts de la scène, nous rappelant qu'à l'ère de la couverture médiatique incessante, le président subit une exposition maximale de sa personne publique, impliquant mécaniquement une diminution du temps consacré à la vie privée. Le sport, à l'interface du public et de l'intime, semble donc un allié de choix pour Obama, confronté à l'impératif d'une double performance, physique (déplacements, discours, image) et théâtrale (avoir « l'air présidentiel », se conformer au rôle défini par les conseillers, feindre la certitude, etc.).

Ces trois anecdotes nous offrent quelques pistes sur le rôle joué par le sport dans l'exercice du pouvoir loin des caméras et des estrades, mais toute généralisation nous semble impossible tant la place du sport dans la vie de tel ou tel individu varie en fonction d'autres influences qui forment sa personnalité.

\section{Le sport et la formation des présidents}

Pour considérer à juste titre la place de la culture sportive dans la formation des présidents, il faut, paradoxalement, se pencher sur d'autres influences. Premièrement, à l'exception de Truman, les dix-neuf présidents étudiés firent des études supérieures et obtinrent leur diplôme de quatrième année, parfois grâce à des bourses du mérite (Clinton) ou sportive (Ford) ${ }^{69}$. Partant, ils ont été au contact du sport universitaire, qui est à partir de 1900 « le laboratoire de l’Amérique à venir », selon la belle formule de Benoît Heimermann ${ }^{70}$. Qu'ils soient joueurs ou entraîneurs, ils furent en partie socialisés dans ce milieu et goûtèrent à la sociabilité sportive. C'est là qu'ils formèrent des réseaux, voire des amitiés, qui les accompagnèrent durant leur carrière politique, puis à la Maison Blanche. À ce titre, les parties de poker de

67 « (...) Any given decision you make you'll wind up with a 30 to 40 percent chance that it isn't going to work out », ibid. ; pour comparaison, les meilleurs joueurs de NBA (basket) ont un pourcentage de réussite d'environ $55 \%$; en MLB (baseball), on estime qu'un joueur exceptionnel réussit une frappe sur trois seulement, soit environ 70 \% d'échec.

68 Un reportage plus récent confirme le rôle du sport dans le quotidien d’Obama, David Remnick, « On and Off the Road with Barack Obama », The New Yorker, 27janvier 2014. http:// www.newyorker.com/reporting/ 2014/01/27/ 140127fa fact remnick?currentPage=all [Lien consulté le 30 juin 2014].

69 Après le lycée, Truman ne put accéder à West Point à cause de sa mauvaise vue et des difficultés financières de son père; il travailla dans une banque, puis à la ferme de ses parents, puis dans une compagnie minière, avant de s'engager dans l'armée en 1917 http:// millercenter.org/ president/truman/ essays/ biography/ 2 [lien consulté le 20 octobre 2012].

${ }^{70}$ Benoît Heimermann, Les Gladiateurs du Nouveau Monde : histoire des sports aux États-Unis, Paris, Gallimard, 1990, p. 61. 
Peter Marquis, « Les présidents américains et le sport : pouvoirs de l'exercice et exercice du pouvoir, de Theodore Roosevelt à Barack Obama », Histoire@Politique. Politique, culture, société, n²3, mai-août 2014 [en ligne, www.histoire-politique.fr]

Truman ou de Eisenhower soulignent que des rapports d'homosociabilité sont fréquents dans le quotidien d'un président, reflet des liens tissés pendant les années de jeunesse lors des entraînements, matchs et après-matchs.

Toutefois, il ne faut pas surestimer le rôle du sport dans la création de ces réseaux : l'armée joua aussi un rôle décisif dans la carrière des dix-neuf présidents étudiés. D'ailleurs, statistiquement, plus que l'origine géographique ou socioprofessionnelle, c'est l'expérience sous les drapeaux qui les rapproche : $42 \%$ des 19 concernés se sont engagés et $16 \%$ ont participé au titre de civils (21\% des deux groupes allèrent au feu) ${ }^{71}$. Truman, par exemple, construisit son réseau sous les drapeaux ; les hommes qu'il dirigea devinrent ses alliés pour asseoir son influence sur la politique locale de Kansas City.

D'autres facteurs expliquent bien entendu l'accession à des fonctions politiques, la famille tout d'abord: Taft intégra les milieux politiques de l'Ohio grâce à son père, Secrétaire à la Guerre de Grant, tandis que le père de Coolidge était un député de l'assemblée du Vermont qui poussa son fils à servir la cause publique; il ne faut pas négliger non plus les réseaux d'anciens élèves (Coolidge et celui d'Amherst par exemple) ou les confréries universitaires (Clinton chez les Alpha Phi Omega de Georgetown).

Cette remise en contexte effectuée, il demeure pertinent de se pencher sur deux cas d'apprentissage de la politique par le sport, celui de Wilson et celui de Nixon. Dans les années 1870, Woodrow Wilson entama des études au College of New J ersey, bientôt rebaptisé Princeton University ; là, il ne jouait pas au football, mais développa un œil acéré pour la stratégie du jeu. Vite, il devint un des cinq étudiants à diriger l'équipe. Il offrait ses conseils en matière de stratégie, de publicité et de financement et parvint à faire éviter la banqueroute en convainquant la direction d'augmenter de 50 dollars courants les frais d'inscription afin de couvrir les besoins de l'équipe en équipement et transport ${ }^{72}$. Il se servit de sa position comme rédacteur en chef du journal étudiant The Princetonian pour faire l'éloge du sport, encourager les étudiants à soutenir l'équipe locale, pousser les joueurs à obéir au capitaine et même justifier le prix élevé du billet. Ses efforts portèrent leur fruit : l'équipe remporta six victoires en six matchs, notamment contre les grandes rivales de Yale et de Harvard. Wilson se réjouit alors dans les pages du Princetonian et révéla le secret de sa réussite : « Notre jeu est plus scientifique que le leur ${ }^{73}$. » Cet épisode clé dans la vie du jeune Wilson a tout d'un apprentissage des fondamentaux de la politique: élaboration d'une stratégie novatrice, mobilisation des ressources locales, formulation d'une doctrine, célébration d'un style distinctif.

Dans une veine similaire, Nixon fit ses armes d'organisateur politique lorsqu'il utilisa le sport comme « dénominateur commun pour révolutionner la vie sociale à Whittier College $^{74} »$. Confronté à la domination d'une«minorité d'étudiants aisés, bien

\footnotetext{
${ }^{71} \mathrm{Si} 36 \%$ des présidents étudiés viennent du Sud, ils sont à égalité ou presque avec l'Est et le Midwest ; $68 \%$ viennent des classes modestes et pauvres ; $32 \%$ des classes aisées et très aisées ; sources : J ohn S. Watterson, The Games..., op. cit. et University of Virginia, « Miller Center », op. cit. ; la taxinomie et les calculs sont les miens.

72 John S. Watterson, The Games..., p. 93.

73Ibid. ; cet accent mis sur la scientificité du jeu se rapproche de l'obsession des membres de la coalition progressiste des années 1880-1920 pour les experts, auxquels on prêtait de pouvoir corriger tous les excès du capitalisme sauvage, voir Pierre Gervais, Les États-Unis de 1860 à nos jours, Paris, Hachette, 2005, chap. 2.

74 Richard M. Collins, « Richard M. Nixon...», op. cit., p. 80.
} 
Peter Marquis, « Les présidents américains et le sport : pouvoirs de l'exercice et exercice du pouvoir, de Theodore Roosevelt à Barack Obama », Histoire@Politique. Politique, culture, société, n²3, mai-août 2014 [en ligne, www.histoire-politique.fr]

habillés et snobs qui régnaient en maître sur le campus par le biais de leur confrérie estudiantine », Nixon rassembla autour de lui les étudiants qui, membres ou proches de l'équipe de football, ne s'identifiaient pas à ce petit groupe. Il put ainsi créer et diriger une confrérie rivale, appelée les « Orthogonians ». Selon Rick Perlstein, il s'apparente en outre à l'acte de naissance d'une politique idiosyncratique de dépréciation de la majorité oppressante et de revendication du statut de victime ${ }^{75}$.

Wilson et Nixon semblent avoir tiré de leur expérience sportive comme organisateurs (manager), et non comme joueurs, le goût de la mobilisation, de la négociation, voire du leadership. Ironie de l'histoire, ce sont ces deux mêmes présidents qui essuyèrent des échecs historiques en termes de capacité à convaincre : Wilson lors de sa tentative de faire entrer les États-Unis dans la Ligue des Nations; Nixon pour persuader le public que ses solutions de sortie à la guerre du Vietnam fonctionneraient.

Si le sport et les valeurs qu'il colporte peuvent sans aucun doute servir d'éducation à la pratique du pouvoir, il ne suffit pas à déjouer les nombreux obstacles qui se dressent entre la volonté politique et son résultat sur le terrain. En tant que matrice de sens et d'action logée dans l'univers large du politique, la culture sportive des présidents mérite d'être insérée dans le renouveau de l'histoire présidentielle telle que la pratiquent depuis une trentaine d'années certains politologues et historiens du politique ${ }^{76}$.

\section{Le sport, révélateur de la personnalité et du style présidentiel ?}

La nouvelle histoire présidentielle insiste sur la nécessité de décentrer le regard audelà de la présidence seule et d'intégrer dans les recherches ses rapports avec le Congrès, l'existence de « régimes » politiques transcendant les administrations présidentielles, ou bien la nature longue et complexe du processus législatif (ébauche, vote, application) ${ }^{77}$. La psychologie aussi est prise en compte: un auteur comme James Barber propose d'analyser la capacité d'un président à mener une politique à l'aune de son appartenance à quatre profils types (actif-positif; actif-négatif ; passifpositif ; passif-négatif) ${ }^{78}$. Intégrer la culture sportive du président dans le renouveau des études présidentielles semble un projet pertinent, car conforme au besoin de décentrer le regard sur les périphériques de l'exercice du pouvoir.

Effectivement, parmi les facteurs qui influencent la politique présidentielle, la personnalité de l'occupant de la Maison Blanche semble jouer un rôle primordial. Le journaliste politique J ohn Dickerson dressa récemment la liste des critères que le public américain devrait retenir pour choisir leur prochain chef d’État ${ }^{79}$. Le plus

\footnotetext{
75 Voir Aaron Astor, "Sarah Palin, Orthogonian», blog:The Moderate Voice, en ligne: http://themoderatevoice.com/37939/sarah-palin-orthogonian/ [lien consulté le 20 octobre 2012] ; Rick Perlstein, Nixonland: The Rise of a President and the Fracturing of America, Simon and Schuster, 2008.

76 Pour l'historiographie, J ulian Zelizer, « Beyond the Presidential Synthesis », op. cit., p. 355.

77 Pour chacun de cesthèmes, David R. Mayhew, America's Congress: Actions in the Public Sphere, Yale University Press, 2002 ; Stephen Skowronek, The Politics Presidents Make: Leadership from John Adams to Bill Clinton, Harvard University Press, 1993; Jeffrey L. Pressman et Aaron Wildavsky, Implementation (...), University of California Press, 1984.

${ }^{78}$ James David Barber, The Presidential Character: Predicting Performance in the White House, rééd., Prentice Hall, 2008. Cette veine historiographique ne semble pas avoir fait beaucoup d'émules et souffre de discrédit.

79 John Dickerson, «How To Measure for a President », Slate, 1er octobre 2012, http://www.slate.com/articles/news and_politics/politics/features/2012/how to measure_a_preside
} 
Peter Marquis, « Les présidents américains et le sport : pouvoirs de l'exercice et exercice du pouvoir, de Theodore Roosevelt à Barack Obama », Histoire@Politique. Politique, culture, société, n²3, mai-août 2014 [en ligne, www.histoire-politique.fr]

important selon lui est la personnalité (character), autrement dit la manière que le président aurait de réagir en temps de crise. Obstacle de taille pour les électeurs, la personnalité est aussi le critère auquel il est le plus difficile d'accéder tant le président est constamment en représentation et veille à la dissimuler derrière des personae de circonstances. Face à cette difficulté, peut-on envisager de questionner la culture sportive d'un président ou d'un candidat afin de décrypter sa personnalité et, partant, sa capacité potentielle à réagir positivement en temps de crise? Ironiquement, c'est ce même J ohn Dickerson, qui répond par la négative: " Mais la façon dont nous finirons par juger la personnalité des candidats est plutôt stupide. On cherche la gaffe commise dans une conférence de presse, on dissèque les repas partagés en couple quand ils étaient jeunes mariés, on analyse leur façon de jouer au basket ${ }^{80}$. »

Relégué au rang d'anecdote insignifiante, la manière dont un homme politique pratique un sport n'aurait, d'après l'auteur, aucun impact sur sa façon de faire de la politique. Sans disposer de davantage de recherches à cet égard, il demeure délicat de se prononcer pour ou contre l'affirmation de Dickerson, mais les nouvelles études présidentielles auraient beaucoup à gagner si elle faisait de la culture sportive du président une sujet d'enquête à part entière.

\section{Conclusion}

En l'état, les savoirs sont donc encore incomplets, mais cet article a tenté de montrer la fécondité des questions que pose une lecture critique de la « culture sportive » des présidents américains. Malgré les difficultés à définir ce terme et à obtenir des résultats empiriques, nous pouvons affirmer que la culture sportive joua un rôle majeur durant les années de formation de la majorité des futurs présidents. Le passage à l'université et la découverte d'une sociabilité sportive nous paraissent à cet égard crucial. Il est également clair que la culture sportive façonne une persona publique que presque tous les présidents ont utilisée pour asseoir leur légitimité comme meneur national, à la fois proche, visionnaire et viril. Enfin, s'il n'est pas certain que la culture sportive influence la prise de décision politique (ou plutôt s'il n'est pas certain qu'on puisse un jour le confirmer ou l'infirmer), on constate que le sport fait de plus en plus partie du quotidien des présidents, sous la forme d'un entraînement à la performance totale qu'est devenue la politique de nos jours. Pour finir, une interrogation s'impose : si une femme était candidate en 2016, comment pourrait-t-elle gagner sans s'approprier cette longue histoire mêlant sport, virilité et imaginaire présidentiel ${ }^{81}$ ?

nt / how to measure for a president temperament is a president s most important attribute and the hardest to examine html [lien consulté le 20 octobre 2012].

80 " (Another idea for improving campaigns is to focus more on the character of candidates, which may get us closer to understanding how they would operate in the Oval Office. That's also a promising notion,) but the way we end up judging candidates' characters is pretty silly-by looking for press conference gaffes, dissecting the meals they ate when they were a young married couple, or assessing the way they play basketball », J ohn Dickerson, « How To Measure..», op. cit., 2012, je souligne.

81 Sarah Palin a su s'approprier cet héritage sportif masculin en tant que candidate à la vice-présidence en 2008, mais aussi dans son émission télévisuelle Sarah Palin's Alaska, cité dans Moore et Dewberry, «The Masculine Image...», op. cit., p. 8-9 ; au contraire Ruth Zylberman et Thomas Snegaroff voient dans le déficit de culture sportive des femmes politiques américaines un obstacle majeur à l'accession à la présidence, voir leur documentaire «Une Présidente pour l'Amérique», Arte France, Zadig Productions, 2012. 
Peter Marquis, « Les présidents américains et le sport : pouvoirs de l'exercice et exercice du pouvoir, de Theodore Roosevelt à Barack Obama », Histoire@Politique. Politique, culture, société, n²3, mai-août 2014 [en ligne, www.histoire-politique.fr]

\title{
L'auteur
}

Peter Marquis, agrégé d’anglais, docteur de l'EHESS (histoire des États-Unis), est maître de conférences à l'université de Rouen où il enseigne la civilisation américaine. Chercheur rattaché à l'ERIAC et au CENA, ses travaux portent sur la culture populaire aux États-Unis, en particulier l'intersection entre le sport et la construction des identités urbaines (voir cv).

\section{Résumé}

De Theodore Roosevelt à Barack Obama, la plupart des occupants de la Maison Blanche cultivèrent des relations étroites avec le sport, soit en affichant leur pratique ou leur intérêt, soit en l'utilisant à des fins de communication pour façonner une persona de chef national proche et viril. Cet article interroge d'abord la place de la culture sportive dans la biographie des présidents étudiés en insistant sur l'usage médiatique qui en a été fait. Il démontre ensuite que cette essence sportive du président est une construction qui mérite réexamen tant du point de vue de la fragilité des corps présidentiels que de l'efficacité communicationnelle ou de la stratégie olympique. La troisième partie est consacrée aux liens entre sport, quotidien de l'exécutif et formation des présidents, à travers un questionnement qui s'inspire de la nouvelle histoire présidentielle (Zelizer, 2002).

Mots clés : États-Unis, exécutif, pouvoir, président, processus de décision, médias, sport.

\begin{abstract}
From Theodore Roosevelt to Barack Obama, most US presidents have established close ties with sport. They either put on public display their ability and taste for sport, or used it as a political prop to mold their persona as the nation's close and manly leader. The article first questions the significance of sporting culture in the presidents' biographies laying emphasis on its media use. It then argues that the essence of the "sports president" is a construct that needs reexamining from the standpoint of the vulnerable presidential body, PR fiascos or Olympic policies. Following the inquiries of the new presidential studies (Zelizer, 2002), the third part is devoted to the intersections between sport, the daily reality of executive power and the formative years of US presidents.
\end{abstract}

Key words : decision-making, executive, media, power, presidency, sport, United States.

Pour citer cet article : Peter Marquis, «Les présidents américains et le sport: pouvoirs de l'exercice et exercice du pouvoir, de Theodore Roosevelt à Barack Obama », Histoire@Politique. Politique, culture, société, nº 23, mai-août 2014 [en ligne, www.histoire-politique.fr] 